Vaccine Centre, Department of Clinical Research, Faculty of Infectious and Tropical Diseases, London School of Hygiene and Tropical Medicine, London, UK

2 Department of Global Health and Development, Faculty of Public Health and Policy, London School of Hygiene and Tropical Medicine, London, UK

beate.kampmann@lshtm.ac.uk Cite this as: BMJ2021;373:n886 http://dx.doi.org/10.1136/bmj.n886 Published: 09 April 2021

\section{Covid-19 vaccines save lives}

\section{Distribution should not be driven by national political priorities}

\section{Beate Kampmann, ${ }^{1}$ Sandra Mounier Jack²}

At the time of writing, over 500 million doses of vaccines to combat SARS-CoV-2 have been delivered worldwide. Not every country has received an equal share, however. The differences in rollout have been criticised, especially in the recent politically driven spats between the EU and the UK. ${ }^{1}$ In Israel, 118 doses per 100 population have now been administered, compared with the UK with 56 per 100; the US with 52 per 100 ; the EU with 19.5 per 100 ; India with 6.8 per 100; and Africa with 0.96 per $100 .{ }^{2}$ It is not difficult to see that things are more equal for some than for others. So how did we get here, does it matter, and if so, for whom?

Vaccine advocates use the hashtag \#Vaccinessavelives on Twitter. Vaccines have, unfortunately, not been able to save lives equally. While countries are trying to "go it alone" and achieve near enough herd immunity to lift their restrictions, maybe the time has come to reconsider what the fundamental purpose of a vaccination programme should be: saving lives, is the simple answer. ${ }^{3}$

\section{Political agendas}

Patient facing healthcare workers are acutely aware of the risk factors associated with poor outcomes of covid-19. Age is the leading factor; hence the decision to prioritise vaccinating vulnerable elderly populations and those who care for them. ${ }^{4}$ While individual countries have scrupulously applied this needs based rationale to organise their own national rollouts, we are now running the risk of a shift to prioritisation driven by national political agendas across the European continent and the world.

Countries will focus their initial response on benefiting their own citizens. For example, the UK managed quickly to obtain upfront investment, approvals, and rollout through a national system. ${ }^{5}$ Supplies were secured through "priority" commercial contracts; the agreement with AstraZeneca gave the UK a head start over Europe. But with around 47\% of its population now vaccinated, and mortality risk for the British substantially reduced, what should the next steps be?

To try to achieve country-wide community immunity (also known as herd immunity) is important, but it should not be the prime objective when global supplies are still limited. "Vaccine greed" has already deprived needy countries of access, not only in Europe, where death tolls continue to rise. That brings not only unnecessary mortality but also potential consequences in fostering new variants that will spread beyond national borders. ${ }^{6}$

\section{Beyond national borders}

We need to move beyond vaccine nationalism and contractual discord between the EU, the UK, and elsewhere. The goal must be ending the pandemic, minimising further morbidity and mortality, and in the process providing mutual economic benefit. It is now time to rethink the prioritisation of access to vaccines by defining target population groups at greatest risk across all countries, and committing the investment required to incentivise the expansion of vaccine production and distribution.

Leadership is needed to facilitate access for the most vulnerable as rapidly as possible, and to reassure communities that the product being offered is indeed safe and effective. Reassuring messages are needed to put observed-but-rare side effects into perspective against the overwhelming benefits of vaccination. Political reactions in Europe have instead resulted in drastic actions, such as stopping entire campaigns already underway. ${ }^{7}$

Such disruptions-amplified by a media frenzy, political posturing, and inadequate industry communication-are adding to existing vaccine hesitancy in some European countries, ${ }^{8}$ such as France, where only $52 \%$ of respondents to a poll by Odoxa state they are very likely or fairly willing to have the vaccine. ${ }^{9}$ The recent AstraZeneca tribulations around clinical trial results ${ }^{10}$ show that clear company communication is critical. Sharing complex trial results through press releases can backfire.

Political leaders in Europe and elsewhere should have been more transparent about likely supply problems, to help manage expectations. Opacity around contract negotiations and the provenance of vaccines and essential components has caused an atmosphere of mistrust in political leaders. Trust is essential for successful vaccine uptake.

If the primary objective of the vaccine is to save lives, then community immunity can be sought once vaccine supply is assured globally and factories involved in the complex and extended supply chains can deliver without obstacles. The vaccine development pipeline looks promising ${ }^{11}$ given the recent regulatory approval for the Johnson \& Johnson vaccine by the US Food and Drug Authority ${ }^{12}$ and results from the NovaVax trials. ${ }^{13}$ Others will follow.

Effective global leadership means ensuring that lifesaving vaccines are available to communities at greatest risk, wherever they are, rather than prioritising community immunity for individual countries while ignoring what happens beyond national borders. 
Competing interests: We have read and understood BMJ policy on declaration of interests and declare the following interests: BK is a principal investigator of non-covid vaccine research studies, some of which are funded by Pfizer. She directs vaccine research at the MRC Unit in the Gambia and at the LSHTM vaccine centre, and she is a member of vaccine advisory boards for Pfizer, Jansen, and GSK. SMJ has no conflicts of interest.

1 Khan Burki T. Challenges in the rollout of covid-19 vaccines worldwide. Lancet 2021;9:42-3.

2 Our World in Data. Coronavirus (covid-19) vaccinations. https://ourworldindata.org/covid-vaccinations.

3 World Health Organization. Covax: working for global equitable access to covid-19 vaccine. www.who.int/initiatives/act-accelerator/covax.

4 Pijls BG, Jolani S, Atherley A, et al. Demographic risk factors for COVID-19 infection, severity, ICU admission and death: a meta-analysis of 59 studies. BMJ Open 2021;11:e044640. doi: 10.1136/bmjopen-2020-044640 pmid: 33431495

5 Department for Business, Energy, and Industrial Strategy. UK Vaccine Taskforce 2020 achievements and future strategy. December 2020. https://assets.publishing.service.gov.uk/government/uploads/system/uploads/attachment_data/file/944308/VTF_Interim_report__5th_publication.pdf.

6 World Health Organization. The effects of virus variants on covid-19 vaccines. 1 March 2021. www.who.int/news-room/feature-stories/detail/the-effects-of-virus-variants-on-covid-19-vaccines.

7 Wise J. Covid-19: European countries suspend use of Oxford Astra Zeneca vaccine after reports of blood clots. BM/2021;371.

8 de Figueiredo A, Simas C, Karafillakis E, Paterson P, Larson HJ. Mapping global trends in vaccine confidence and investigating barriers to vaccine uptake: a large-scale retrospective temporal modelling study. Lancet 2020;396:898-908. doi: 10.1016/S0140-6736(20)31558-0 pmid: 32919524

9 Oui à la vaccination ... mais pour les autres. [French] Odoxa. 4 January 2021. www.odoxa.fr/sondage/oui-a-vaccination-autres.

10 Joseph A. "I was sort of stunned": Fauci and US officials say AstraZeneca released "outdated information” from covid-19 vaccine trial. 23 March 2021. www.statnews.com/2021/03/23/astrazeneca-may-have-used-outdated-information-in-announcing-covid19-vaccine-results.

11 Covid-19 vaccine tracker. https://vac-Ishtm.shinyapps.io/ncov_vaccine_landscape.

12 Johnson \& Johnson. Johnson \& Johnson covid-19 vaccine authorized by US FDA for emergency use: first single-shot vaccine in fight against global pandemic. 27 February 2021.

www.jnj.com/johnson-johnson-covid-19-vaccine-authorized-by-u-s-fda-for-emergency-usefirstsingle-shot-vaccine-in-fight-against-global-pandemic.

13 Madhi SA. Results from Novavax vaccine trials in the UK and South Africa differ: why, and does it matter? 1 February 2021. https://theconversation.com/results-from-novavax-vaccine-trials-inthe-uk-and-south-africa-differ-why-and-does-it-matter-154293.

This article is made freely available for use in accordance with BMJ's website terms and conditions for the duration of the covid-19 pandemic or until otherwise determined by BMJ. You may use, download and print the article for any lawful, non-commercial purpose (including text and data mining) provided that all copyright notices and trade marks are retained. 